\title{
IOANNES ANASTASIUS VELUANUS ${ }^{1}$ )
}

DOOR

Dr. F. P IJ P E R.

De Gereformeerden of Herrormden zijn gekant tegen uiterlijke teekenen in de godsdienst. Dit belet evenwel niet, dat in sommige van onze kerken borden hangen, waarop de namen geschilderd staan van de predikanten die de gemeente gediend hebben. Als zulk een middel om de gedachtenis van een edelen voorganger levendig te houden beschouwe men het gedenkteeken, dat zoo aanstonds onthuld zal worden.

In de oogenblikken die ons worden toegemeten zal het niet mogelïk zijn alles aan te roeren wat wij op het hart hebben. Wie omtrent de historische beteekenis van Joannes Anastasius Veluanus vollediger wenscht ingelicht te worden, gelieve. zich to wenden tot geschriften van Moll e. a., inzonderheid tot het $4^{\text {de }}$ deel der "Bibliotheca reformatoria neerlandica", waarin de werken van Anastasius herdrukt zijn.

1) Rede gehouden bij de onthulling van het gedenkteeken te Garderen, in tegenwoordigheid van Z. K. Hoogheid Prins Hendrik der Nederlanden, op 30 Juli 1912. 
Allereerst een woord over zijn leven. Dit leven is een voortdurende strijd geweest. Zijn grootvader, Jan Dyricksz Versteghe, eigenaar van de nog bestaande hofstede $\mathrm{D}_{\theta}$ Steeg te Stroe, moet een zekere welvaart genoten hebben. Maar zijn vader, Gerrit Jansz Versteghe, is jong gestorven, en bij diens ontijdigen dood bleef zijne moeder in bekrompen omstandigheden achter. Zoo werd hï reeds in de kinderjaren bij de hand genomen door den ernst, tweelingbroeder van den rouw.

Hij werd bestemd roor den geestelijken stand. De roeping kan tot hem gekomen zijn op de plek waar wij ons thans bevinden. Immers hier stond de oude kerk, gebouwd in 1050, toen reeds eerbiedwaardig om baren ouderdom. Naar deze zelfde plek was hij gewoon met zïne moeder op te gaan om den eredienst bij te wonen, om te luisteren naar de prediking en het godsdienstig onderricht. En hier, in de onmiddellijke nabijheid, waarschïnlijk in de kerk, was vaders graf.

Geestelïke te worden, zijn leven aan den dienst van God te wijden, welk een schoon doel! Maar hoo dit te bereiken? Voor een kind, te Stroe geboren, waren hieraan zeer groote moeilÿkbeden verbonden. Hoe deze moeilijkheden overwonnen werden, valt niet te zeggen. Welke । scholen hï bezocht, is tot heden niet ontdekt geworden. Waarschijnlijk heeft hij de lessen gevolgd van de toen zeer vermaarde hoogeschool van Harderwïk, die honderden leerlingen telde. Onder hare leeraren, ook in den raad der stad en onder de geestelijken aldaar waren er die overhelden naar de Hervorming. Te Harderwïk kan hï zijne kennis van Grieksch en Latïn hebben opgedaan, talen, waarin hij rolgens het getuigenis van den inquisiteur Sonnius zeer ervaren moet geweest zijn. Ook het Hebreeuwsch heeft hij zich eigen gemaakt, hetzij daar of elders. Waarschïnlijk heeft hij te Harderwijk do studie begonnen van de oude kerkvaders of Christelijke schrijvers der eerste eeuwen, wier werken hem later zooveel licht en steun hebben verschaft.

In 1540 , vermoedelïk nog als student, heeft hij een 
aanvang gemaakt met het lezen van de geschriften der Hervormers, die van Luther en Bullinger, de „Loci communes" van Melanchthon, en de Institutie van Joannes Calvijn. Er is grond om aan te nemen, dat hij tïdelïk ook de bisschoppelijke school te Utrecht heeft bezocht. Zijne leermeesters daar zullen in hem een jongen man van groote bekwaambeden erkend hebben, maar tegelijkertijd moet zijne gehechtheid aan de Roomsche kerk hun twïfelachtig zijn voorgekomen. Het heeft hem niet belet van den bisschop de priesterwijding te ontrangen.

In 1544 wordt hij pastoor te Garderen.

Is hij gelnkkig? Neen. Met eene inwendig verscheurde ziel heeft hij zijn ambt aanvaard. Heeft hij bet schoone doel, priester te worden, wat hij in zijn jeugd als het toppunt zijner wenschen beschouwde, dan niet bereikt? $\mathrm{H}_{\mathrm{ij}}$ is teruggekeerd naar dezelfde kerk, die hij in zijne jeugd beeft betreden. Weder omringen bem de bekende wanden; hij aanschouwt het Maria-beeld, waarvoor hij lang geleden zijn "Wees gegroet, Maria" heeft opgezegd; de beeldjes ran de heiligen Gangulphus en Antonius, waarvoor hij als kind de knietjes gebogen heeft. Maar hoe anders kwam hij terug dan hij is heengegaan! Als hij in plechtgewaad binnentreedt om naar het altaar te schrijden, zijn aller oogen op hem gericht, daaronder die van zïn grootrader en van zijne moeder. Heilige weelde voor het moederhart, niet waar? En dankbaarheid in het hart van den zoon....

Maar straks als het oogenblik is aangebroken om den kansel te beklimmen, wat moet hij dan prediken? Kan hij alles openbaren wat er woelt in zijn gemoed? Kan hij de gemeente deelgenoot maken van zijne geheimste gedachten? De menschen die hem lief hebben en vertrouwen, inwïden in zijne twijfelingen?· Moet hij zeggen : verwerpt de heiligen-vereering, doet die beelden van Maria, van Gangulphus en Antonius weg, want God is een geest, en die Hem aanbidden, moeten Hem aanbidden in geest en in waarheid? Moet hij verkondigen: Jezus Christus is uw eenige middelaar, maar niet de heiligen? Verklaren; 
belïdt uwe zonden niet aan mü, priester, maar belijdt ze aan God? Zoekt het niet in mijne vrijspraak, maar gelooft, dat Gods oneindige liefde in Christus $u$ vergeven wil? Het moeilïkst is voor hem de altaardienst. $\mathrm{Hij}$ moet in de mis over brood en wijn zekere woorden spreken, en verrolgens aannemen, dat zij veranderd (getranssubstantieëerd) zijn in het echte vleesch en bloed des Heeren, hetzelfde vleesch, waarmede hij geboren is uit Maria en gebangen heeft aan het kruis. Verzekerd, dat nu de Heer zelf in brood en wijn aanwezig is, moet hij de gemeente voorgaan met er de knieën voor te buigen, hij moet het brood opheffen om het door al de aanwezigen-als God te doen aanbidden. Maar hoe, als hij zelf, de voorganger, twijfelt? Hoe, als dat wonder der transsubstantiatie eens niet plaats heeft? Hoe, als dat brood niet verandert? $\mathbf{Z}$ ware verantwoordelijkheid voor den priester, die zich afvraagt, of hï mag aansporen tot afgoderï?

$\mathrm{Om}$ dezen strijd goed te doorgronden, moeten wij verder bedenken, dat niet alleen de geheele Veluwe met inbegrip van Garderen, maar gebeel Gelderland, ja, Nederland in 1550 althans officiëel, voor de wet, nog een Roomsch-Katholiek land was. In een deel van Duitschland en Zwitserland, tijdelijk ook in Engeland, bestonden toen reeds Protestantsche kerken. Maar in ons vaderland - wat er ook gistte onder de bevolking - werd tijdens de regeering van Karel $V$ de Roomsch-Katholieke kerk als alleenheerscheresse door het openbaar gezag krachtig gehandhaafd. Zoowel door den paus als door den keizer waren inquisiteurs aangesteld, die de aanhangers der Hervorming opspoorden, en door de rechtbanken deden veroordeelen, dikwijls tot zware straffen, soms tot den dood. Er behoorde moed toe roor eene afwijkende overtuiging uit te komen.

Dien moed heeft Joannes Anastasius bezeten. Twïfelingen, vrees heeft hij overwonnen. Op de studeerkamer schrijft hij een boek ter bestrïding van het pausdom. In zajne prediking maakt hï zich los van het verleden, en waagt het mede te gaan met de nieuwe beweging. Hij 
aarzelt niet meer, hij moet voort. Dubbelzinnig drukt hij zich niet meer uit, hij legt bloot wat hij als waarheid heeft erkend. Tot zijne verrassing baart deze openhartigheid aan de gemeente geen schrik. Velen gaan, zij het schoorvoetend, met hem mede. Weldra gevoelen zij zich, gelukkig met hunnen voorganger, die hen immers onderricht, vragen oplost, nieuwe vertroosting brengt. En de voorganger gevoelt zich gelukkig met zijne gemeente. Het duurt slechts kort.

Op den Nieuwjaarsdag van 1550 verschijnen twee gerechtsdienaars in het dorp; zij begeven zich naar de pastorie, nemen den pastoor gevangen en voeren hem naar Arnhem. Wat is daar met hem geschied? Welke bedreigingen heeft Sonnius, de geloofsrechter, tegen hem geuit? Met welke ontzettende vooruitzichten heeft men hem aan het wankelen gebracht? Waar is zijn moed gebleven? Hij verklaart zich bereid to herroepen. Reeds den 27sten Januari is zijn ronnis gereed. Hij ontkomt aan den dood. Eeuwigdurende gevangenschap zal zijn deel wezen. Op gemelden datum leest hij in de Groote kerk te Arnhem ten aanhooren van eene onafzienbare schare zijne herroeping voor. Tot verbazing van vele aanwezigen dio hem kennen, edellieden, burgers en boeren, verklaart hij de Protestantsche leer te verwerpen en de Roomsch-Katholieke aan te hangen. Beklagenswaardige man: de berroeping is niet oprecht! In een rampzaligen toestand wordt hij gebracht naar het oude, bouwvallige kasteel te Hattem, en opgesloten op een der torens, waar hij om den anderen dag heeft te vasten op water on brood. Wanneer hij later wat meer vrijheid van beweging erlangt, is dit bijr. om naar de kerk te gaan, en als

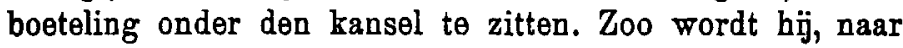
zijn eigen woorden, door Sonnius voortdurend met groote schande voor de menschen beladen. Als hij op het kasteel, boven in zijn torenvertrek, den blik laat weiden over den omtrek, over de oevers van den IJsel, welke vruchtbare velden, welke prachtige vergezichten! Maar binnen in zijne ziel heerscht eene stikdonkere nacht. Hij wordt ver- 
teerd door wroeging. Hij is tot het laagste punt in zijn leven verzonken.

Toch laat de goddelïke genade hem niet los. Én is er die het gekrookte riet niet verbreekt en de rookende vlaswiek niet uitbluscht. Vrienden te Arnhem en to Utrecht drongen bij Sonnius op zijne loslating aan. Het antwoord was, dat hij zou worden rrijgelaten, als hij een boek schreef ter verdediging van het pausdom gelijk hij er vroeger een begonnen was te schrïjen tot bestrijding daarvan. Voor dit doel verschafte men hem den Bïbel en een groot aantal oude schrijvers. Het verlangde boek kwam echter niet uit zïne handen. Wel zag -men hem ijverig studeeren, maar voor zich zelf deed hij dit met een ander oogmerk. Weldra wist de machtige invloed zijner beschermers bij de landroogdes Maria te Brussel zijne vrijlating te bewerken, onder voorwaarde dat hij naar de hoogeschool te Leuren zou gaan, daar in zijn onderhoud zou voorzien door het verrichten van diensten in de St.-Jacobskerk, en gedurende drie jaren zou studeeren in de Roomsch-Katholieke theologie. Voor de nakoming dezer voorwaarden moet een borgstelling gestort worden ten bedrage van vierhonderd gulden. Twee personen hebben hem toen de reddende hand toegestoken, zijn trouwe grootvader, de oude Jan Dyricksz Versteghe, die voor driehonderd gulden, en een vriend, de landbouwer Evert Arentz to Stroe, die voor honderd gulden borg sprak. $\mathrm{Hij}$ is ook naar Leuven gereisd, beeft er drie dagen vertoefd, waarschijnlijk eenige malen om de St.Jakobskerk heengewandeld, en is toen gevlucht, men weet niet recht waarheen, misschien naar Duitschland. Zoo had hï dan schijnbaar alles verloren. Zijne goederen waren reeds lang verbeurd verklaard. De borgstelling was wèg. En het vaderland lag voor altijd achter hem.

En toch haalde hij ruimer adem. Eøn kostelïk goed had hï herwonnen: de vrijheid. Én ding had hï niet verloren: zj̈ne godgeleerde ontwikkeling. Hij blaakte ran geestdrift om zijne kennis dienstbaar te maken aan hetgeen hij als waarheid had erkend. En tegenover zijnen 
diepen val bezielde hem slechts deze éne zucht: de begane fout zooveel mogelijk te herstellen, de achting zijner bloedverwanten, vrienden en bekenden te heroveren, rust te vinden roor het gefolterde geweten, door daden te toonen, dat hij een nieuw mensch geworden was. De eerste daad moest het boek zijn dat in 1554 te Straatsburg verscheen: „Der Leken wechwyser". Op den titel noemde hij zich nu voor het eerst: "Joannes Anastasius Veluanus". Anastasius, d.w.z. de herrezene, de opgestane, die uit den dood tot het leven herboren is. Het schitterende boek is gedeeltelijk in den winter, onder_armoedige omstandigheden, terwijl het vuur hem ontbrak om zijn vertrek te verwarmen, geschreven. Ofschoon het ruim $\mathbf{5 0 0}$ bladzijden beslaat, kwam het in een halfjaar gereed. Het was de rijpe vrucht van lang nadenken. Het was de niet meer in te houden uiting van hetgeen reeds jaren gekookt en gebruist had in zijn gemoed, de kreet van het geweten, dat niet langer zwijgen kòn. Door de voorbereiding in stilte wordt ook eenigszins verklaard, dat de inhoud zoo geleerd is. Behalre op de Duitsche en Zwitsersche Hervormers beroept bij zich ontelbare malen op Tertullianus, Cyprianus, Origenes, Ambrosius, Chrysostomus, Hieronymus, Augustinus. Hij voert zelfs nog een groot aantal andere schrijvers aan. Hoe was het mogelijk in zoo korten tijd dit alles bijeen te brengen? Maar in de pastorie te Garderen, op den slottoren te Hattem had hï immers voorstudiën en ontwerpen gemaakt. In vele folianten kende hij den weg. Hij had het boek reeds in het hoofd, voordat het op schrift werd gebracht. Uit tal van oude schrijvers weet hï plaats na plaats aan te halen op eene wijze die den deskundige met bewondering vervult. Het best begrijpen wij de wording $\operatorname{ran}$ dit meesterwerk, als wij bedenken, dat het geschreven werd met zijn hartebloed, dat hij bij nacht en bij dag, in brandenden zielenood over den inhoud had nagedacht.

Waarom betitelt hij het als „Der Leken wechwyser"? Omdat hï het niet bestemt voor geestelijken, maar voor IX. 


\section{2}

lezers uit alle standen, voor hooggeplaatsten en eenvoudigen. Het wil echter niet zeggen, dat hï denkt aan onontwikkelden. Hij rekent op welonderwezen lezers, die zelfstandig kunnen oordeelen, en desverkiezende de bijgebrachte aanhalingen in het Grieksch of Latijn kunnen naslaan en vergelijken. Waarom noemt hij het een "wechwyser"? Hoofdzakelijk omdat hij de leeken wil aansporen om te doen wat de geestelijken nalaten. Hij wanhoopt er aan, dat de kerk zich zelf zal herrormen; dat de priesters en bisschoppen met den paus aan het hoofd de heerschende dwalingen en misbruiken zullen ter zijde stellen. Reeds zoo lang heeft men geroepen: hervorming! hervorming van de kerk in hoofd en leden! Maar het is alles gebleven bij het oude. De misbruiken zijn te zeer vastgeworteld, de dwaling vindt zoovele en zoo aanzienlijke verdedigers. Welnu, waar brand is, laat blusschen wie blusschen kan! Als de geestelijken weigeren te doen wat men van hen verwachten mag, laten dan de leeken handelen. Willen de bisschoppen geen predikanten ordenen die zich in hunne prediking enkel naar de Schrift richten, laten dan de geloovigen samenkomen om zulke predikanten te beroepen. Zijn de geestelijken niet te bewegen om de beelden uit de kerken te verwijderen, dan moeten de leeken ze maar wegnemen. Vooral legt Anastasius nadruk op hetgeen hij beschouwt als den plicht der landsheeren, nl. om in hun gebied met krachtige hand de Hervorming in te voeren. Hierbij dejnst hij er niet voor terug hun voor te houden, dat meermalen staten waarin de aanhangers der ware godsvereering vervolgd werden, zijn te gronde gegaan. Verandering, zegt hij, in het hoogste bestuur des lands om de wille van Gods Woord is rolgens de Schrift meermalen geschied en zal ook thans niet uitblijven. Gods hand is niet verkort om tronen neder te werpen of op te richten. Denkt men hierbij aan het geen weinige jaren later in ons vaderland is geschied, aan Hagepreek, Beeldenstorm, het begin van den 80-jarigen oorlog en de afwerping van het Spaansche juk, dan rraagt men zich af, welken in- 
vloed "Der Leken wechwyser" wel kan gehad hebben? Toch meene men niet, dat het boek geschreven zou zijn in een oproerigen toon, in een geest van omverwerping. Integendeel: het doel is op te bouwen. De schrijver behandelt in beknopten vorm alle artikelen der geloofsleer. Hij vangt aan met God, Gods tegenwoordigheid, de personen in de godheid, de godheid des Zoons, Christus' menschbeid, en den H. Geest. $\mathrm{Na}$ aldus het Wezen der Wezens besproken te hebben, gaat hï over tot den mensch, des menschen wil, den zondenval, de bekeering, het berouw, het goede voornemen, het geloof, de rechtvaardigmaking, de liefde tot God en menschen. De hoofdstrekking is dezelfde als bij alle Hervormers: dat behoudenis alleen gevonden wordt in het geloof, in de verzekerdheid dat Gods oneindige Vaderliefde ons om Christus' wil vergeeft, ons maakt tot een nieuw schepsel, ons de aanneming tot kinderen schenkt. Over kleine verschilpunten tusschen hem en Luther of Calvijn, mag worden gezwegen. Dat hij een zelfstandig godgeleerde was, en eene zuiver Nederlandsche Reformatorische richting vertegenwoordigt, is-elders aangetoond. Het is wel de moeite waard te weten, dat de Hervormingsgezinde beginselen in Nederland een eigen ontwikkeling hebben gevolgd, en dat Joannes Anastasius daartoe veel heeft bijgedragen. Doch thans zoeken wij in hem slechts, wat hem met de andere Hervormers vereenigt. Dit is geheel in zijn geest; want eerder dan iemand heeft hij gepleit voor verdraagheid tusschen de Protestanten onderling, voor toenadering en verzoening. De Roomsch-Katholieke leeringen en gebruiken bestrijdt hij, hierbij legt hij een belangrijke kennis der geschiedenis aan den dag en tracht aan te wijzen, wanneer elk van die Roomsche leeringen of gebruiken in de Christelijke kerk is opgekomen. Doch altijd weder keert hï terug tot de hoofdzaak, tot de onderrichting zijner lezers, in hoofdstukje na hoofdstukje, orer onderwerp na onderwerp.

Alles tezamen genomen is zïn werk een volledig handboek van de Protestantsche geloofsleer geworden. Het is 
het oudste handboek van dien aard in Nederlandsche taal. Geen boek was beter geschikt dan "Der Leken wechwyser" om de zaden der Hervorming uit te strooien in Nederlandsche harten. Niemand heeft meer dan Joannes Anastasius Veluanus aan de aanhangers der Herrorming in Nederland grond onder de roeten gegeren, hen gewapend om de tegenstanders te woord te staan.

Behalve dat dit boek het godsdienstig inzicht heeft verhelderd, aan hoevele harten die in onvrede met God leefden, heeft het vrede gebracht? Aan hoevele geslingerde gemoederen heeft het in leven en in sterven troost geschonken? Hoevelen zelfs die verleerd hadden de knieën te buigen roor een Opperwezen, hebben er hunnen Hemelschen Vader door wedergevonden? Stellig heeft het sommigen die hunnen Heiland verloren hadden doen uitroepen tot Christus : mijn Heer en mijn God!

Omtrent Anastasius' verderen levensloop was nog slechts weinige jaren geleden zoo goed als niets bekend. Sedert zijn enkele belangrijke zaken aan het licht gekomen. Duitschland is een tweede vaderland voor hem geworden. "Der Leken wechwyser", in den eersten druk in den Gelderschen tongral opgesteld, was roor onze Duitsche naburen gemakkelijk verstaanbaar. Het boek heeft aan den schrijver eene eervolle loopbaan bezorgd. Of hij in den eenen of anderen vorm aan de vermaarde school van Monhemius te Dusseldorp verbonden is geweest, kan niet met zekerheid worden vastgesteld. In 1557 wordt hij predikant te Bacharach, een bekoorlïk gelegen stadje aan den Rijn, in het gebied van keurrorst Otto Hendrik van de Palts. Thans breken betere dagen voor hem aan. Wel levert zijne positie een zeer groot verschil op, vergeleken met de ellende en de vernedering, jarenlang op het slot te Hattem doorgestaan! Voor gebrek heeft hij thans overvloed; in plaats van oneer valt hem eer te beurt; de gedwongen werkeloosheid is vervangen door het heerlijke werk van den evangelie-dienaar!

Toch wordt ook hier de strïd hem niet gespaard. Bo 
slister dan vroeger doet hï zich thans kennen als aanhanger der Gereformeerde leer. Dit berokkent hem de bittere vijandschap van zekere aanhangers van het Lutheranisme, die zelfs aandringen op zijne afzetting en verbanning. Weldra door de troonsbeklimming van den bekenden keurvorst Frederik III werden zijne omstandigheden weder gunstiger. Laatstgenoemde vorst toch, de Gereformeerde leer van harte toegedaan, heeft Anastasius tot den rang van superintendent verheven. Het is merkwaardig te zien, hoe spoedig en met hoe goed gevolg de Gereformeerde beginselen daar ginds in alle onderdeelen van het kerkelijke leven in toepassing werden gebracht. Het zou moeilijk vallen eene landstreek aan te wijzen waar, onder eene Gereformeerde kerkordening, het godsdienstig en kerkelijk leven in weinig jaren tot grooter bloei gekomen is dan in Bacharach en onstreken tijdens en na het superintendentschap ran Joannes Anastasius. Maar de Lutherschen zijn voortgegaan hem te bestrïden, betgeen hem zeer veel leed heeft veroorzaakt. Hij verweerde zich o. a. door het schrijpen van een tweetal boeken, waarvan ons het bestaan nog slechts kort bekend is. Eene heerlijke voldoening moet het hem verschaft hebben te mogen medewerken aan de totstandkoming van den Heidelbergschen Katechismus, bet prachtige boek, waaruit geslachten na geslachten zooveel leering geput hebben. Deze katechismus is ten deele de vrucht geweest der samenwerking $v a n$ de superintendenten der Palts, wier vergaderingen Anastasius moet hebben bïgewoond. $\mathrm{De}$ inhoud vertoont onmiskenbare verwantschap met dien van „Der Leken wechwyser". Dezelfde verlichte, prome geest komt er ons in te gemoet. Geen geringe eer voor onzen bescheiden landgenoot, die binnen de gemeente Garderen het levenslicht had aanschouwd, een belangrïken invloed te mogen oefenen op een geschrift, dat voor alle Gereformeerde kringen in alle landen en werelddeelen het godsdienstige leerboek bij uitnemendheid geworden is.

En thans wordt te Garderen een gedenkteeken roor 
hem onthuld. Waarom geschiedt dit? Foorzoover deze vraag in het voorafgaande niet voldoende beantwoord is, zij het mij vergund nog een duidelïker bescheid te geven.

Waartoe een gedenkteeken voor Joannes Anastasius Veluanus? Neen, hij behoort niet tot degenen die reeds door hunne geboorte aanspraak schïnen te hebben om in marmer of brons vereeuwigd te worden. Maar kan iemand, wiens wieg gestaan heeft op de Steeg te Stroe, boe klein en nederig voor de wereld, ook groot zijn roor God?

Neen, niet op het gebied der fraaie letteren heeft bij lauweren verworven. Geen dichter was hij, geen schepper van bevallige of roerende rerhalen. Hij was niet toegelaten tot den Parnassus der bevoorrechten, wier namen op aller lippen zweven, wier liederen in ieders mond zän, on voor wier standbeeld alle beurzen worden geopend. Maar eilieve, mag soms ook iets worden gedaan voor de gedachtenis van een godgeleerde en evangelie-dienaar? Mag ook eenige belangstelling worden verwacht voor iemand die niet vermaakt, maar onderwïst, die niet streelt, maar vermaant, niet met bloemen bestrooit, maar vertroost, niet den zondaar zondaar laat, maar hem oproedt voor de eeuwigheid, oproedt roor God?

Neen, niet op het slagreld heeft Joannes Anastasius roem geoogst. Een veldheer was bij niet, geen zeeheld. Niet onder bloedvergieten heeft hij zijn land en volk gediend. Doch misschien zal men erkennen, dat er nog plaats is voor een gedenkteeken van een man des vredes, wiens roeping het was verzoening te prediken en het eeuwige leven.

Waartoe een monument roor Joannes Anastasius $\mathrm{Ve}$ luanus? Omdat hij voor de goede zaak zooveel geleden, alles opgeofferd heeft. Geen martelaar is hij geworden; zijn bloed heeft niet gerloeid. Maar de smarten die hij heeft uitgestaan, hebben zooreel langer geduurd; de angsten die zijne ziel gefolterd hebben, verrolgden hem jaren. Wel mag men hem dan rekenen tot dat groote geslacht der 16de eeuw, dat voor de hoogere dingen alles heeft reil gehad. Zijn zij talrïk, de mannen of rrouwen 
van wie men dit getuigen kan? Ontmoet men ze dagelijks, de edele harten, voor wie het eigenbelang zoozeer op den achtergrond staat bij het belang der waarbeid, het tijdelijke bij het eeuwige, het aardsche bij het hemelsche? Wij, in onze hooggeroemde twintigste eeuw, wat aanschouwen wij? Koelheid of warmte? Onverschilligheid of geestdrift? Berekening of toewijding? Hoe plat, hoe gelijkvloersch, hoe alledaagsch is de levensopvatting van de meesten! Geldzucht, eerzucht bewegen er velen. Maar waar is het karakter? Waar is de bereidheid om voor de hoogste en heiligste dingen pal te staan? Hoe groot is in dit opzicht het geslacht geweest van de baanbrekers der Herrorming! Hoe ver steken zij buven ons uit, zij, die voor de onzienlijke goederen tot in den dood gestreden en geleden hebben! Sommigen hebben er het hoofd voor onder den bijl gelegd. Anderen hebben er den brandstapel voor beklommen. Laten de ouders het vertellen aan de kinderen en dezen weder aan de kindskinderen, opdat zij weten, voor welken prïs de Hervorming voor ons verkregen is!

Waartoe een gedenkteeken roor Joannes Anastasius Veluanus? Omdat wij de beginselen der Hervorming willen handhaven, de overgeleverde goederen bewaren. De Roomsch-katholieke godsdienst, die eenmaal de godsdienst was van onze voorouders, laten wï in hare waarde. Ook aan gindsche zijde wordt het evangelie van Jezus Christus verkondigd, zij het naar onze meening onder een deksel. Er worden harten verteederd door de verteederingen der Christelïke liefde, er wordt gehoopt, geloofd en gebeden. Geen oordeel matigen wij ons aan over al de wegen waarop de sterveling den Eeuwige zoekt. Dàt zij overgelaten aan de Voorzienigheid, te beslissen waarom zij God aanbidden en verheerlijken in dien rorm en wij in dezen. Ook het verleden, de herinnering aan vroegeren strïd mag ons niet verhinderen om broederljjke gevoelens to koesteren. Laten oude veeten vergeten zijn! Wij weten dat Jezus Christus heeft gezegd: hieraan zullen allen erkennen, dat gï 
mijne discipelen zijt, zoo gij liefde hebt onder elkander. Maar verder aan onzen kant geen aarzeling! Geen twïfel of ons in de Hervorming een kostelijk goed geschonken is. Aan ons de plicht een 200 groot mogelijk aantal aan dat goed deelachtig te maken. Een licht is voor onze oogen opgegaan. Aan ons de taak er voor te waken, dat dit licht niet gedoofd worde, maar in helderen luister blijve stralen. Vooral Joannes Anastasius is geschikt ons hiorin aan te vuren. Want hij vertegenwoordigt het Protestantisme in zijne beste gedaante. Heeft niet bij vooral aangedrongen op de noodzakelijkheid van wedergeboorte naast geloof? Tot de schoonste- bladzijden van "Der Leken wechwyser" behooren die waarop hij den lezers voorhoudt, dat "de vrucht des geestes is liefde, blijdschap, vrede, lankmoedigheid, goedertierenheid, goedheid, vertrouwen, zachtmoedigheid, ingetogenheid". Heeft hij niet toornig de hand opgeheren tegen die Protestanten die, uit misverstand en lichtzinnigheid, meenden in hun geloof een rrijbrief te bezitten om Gods heilige geboden in den wind te slaan? Indien iemand dan leert hij ons, dat het ware Protestantisme ernst, vroomheid, dat het een leven met God is, een godsdienst, waarin alles aankomt niet op het uiterlijke, maar op het innerlijke, niet op den vorm, maar op het wezen, niet op de ceremoniën, maar op den geest. Die godsdienst willen wij handhaven, als de kostelijkste erfenis voor de nakomelingschap bewaren!

Waarom een gedenkteeken voor Joannes Anastasius? Daarroor bestaat ook eene nationale reden. Aan velen is de geschiedenis der Herrorming in Duitschland en Frankrijk beter bekend dan die in Nederland. Toch is de Hervorming in ons vaderland even gewichtig als elders. Zï heeft zelfs hare eigen ontwikkeling, hare eigen leidslieden, hare eigen predikers en schrijvers, hare eigen martelaren. Ja, in geheel Europa zijn Nederlanders de eersten geweest, die hun bloed voor de Herrorming vergoten hebben. Moeten nu wij en onze kinderen, wij Nederlanders, ook een Herrormer kennen die een zoon van Nederland, die vleesch is van ons vleesch en bloed 
van ons bloed? Toen de geschiedschrijver Moll omstreeks het jaar 1855 de buurtschap Stroe en de hofstede De Steeg bezocht, bemerkte hij tot zijne verbazing, dat de naam van Joannes Anastasius Veluanus zelfs in zijne geboorteplaats volstrekt vergeten was. Sedert is hierin veel veranderd en door de oprichting van dit gedenkteeken is de aandacht roorgoed op hem gevestigd. Dit is het eerste monument voor de Herrorming in Nederland. Mocht er toch eens een einde komen aan de vergetelheid waarin zoovele groote en edele Nederlanders bij hun eigen volk verzonken zijn! Mocht de dag aanbreken, waarop ieder kind in Nederland zal weten, wie de groote martelaren en leidslieden der Herrorming in ons vaderland, wie Joannes Pistorius, wie Angelus Merula, wie Guido de Bres, wie Joannes Anastasius waren! Vooral dan zal het goed zijn, als zij een klaar besef bezitten van de zaak waarvoor die edele voorgangers zijn opgekomen.

Behalve door Hervormden of Gereformeerden zijn giften voor het gedenkteeken geschonken door leden van verschillende andere kerkgenootschappen. Hunne opvattingen zijn mild genoeg om te veroorloren, dat wij onze hulde aan Joannes Anastasius gedeeltelijk brengen als eene hulde aan de Gereformeerde beginselen. Hoe zwak was het plantje van de Gereformeerde kerk toen, en welk een sterke, wijdvertakte boom is het thans! De Gereformeerden van alle schakeeringen tezamengenomen vormen verreweg de meerderheid van alle Protestanten. In Duitschland, in Zwitserland, in Frankrijk, in Engeland, in ZuidAfrika, en rooral in het groote land over den Atlantischen Oceaan, de Vereenigde Staten van N. Amerika, hoevele tientallen van millioenen! Hetzij men met de Gereformeerde leer volledig instemme of niet, ieder zal moeten erkennen, dat zij gewerkt heeft als een krachtige zuurdeesem, dat zij grooten invloed heeft geoefend op de geschiedenis der volken. Wij waardeeren haar als een weldadig, een behoudend element in het Protestantisme. De Gereformeerde godsdienst in zijn zuiversten rorm is altijd 
een verlichte godsdienst geweest, waarin zoowel de rechten van het verstand als die van het gemoed geëerbiedigd werden, waarin duisternis en onwetendheid werden geschuwd, het wetenschappelijk onderzoek voorgestaan; een godsdienst, de volstrekte afkeөr van femelarị, van eөn willoos, zoetelijk voortdrijven op de wateren van het gevoel; een godsdienst zoowel van onwrikbaar vertrouwen op de Voorzienigheid als van krachtig handelen. Wie zal, vooral lettende op de geweldige uitbreiding van dit Gereformeerde Protestantisme in N. Amerika, uitmaken welke beteekenis voor de wereldgeschiedenis dit nog verkrijgen zal?

Doch op deze wijze wil ik niet roortgaan. Onze hulde moet de gemeenschappelijke hulde van het Nederlandsche Protestantisme zijn. Laat de Doopsgezinde in Anastasius eeren, wat hij in hem waardeert; de Lutheraan denzelfden Hervormer huldigen voor hetgeen hem aantrekt, de Remonstrant en de Hervormde hem ieder voor het zijne dank toebrengen. Zoo handelen wij het best in zijn geest, daar hij mildheid voorstond, zachtmoedigheid, vrede. Dit was ook de geest van Willem van Oranje, den vader des vaderlands. Wij hebben well behoefte aan meer eendracht. 0 mijn verdeelde vaderland! Mijn door partijschappen verscheurde Protestantsche Nederland! Land, waarin het zoo dikwijls vergeten wordt dat wij gemeenschappelijke idealen hebben, dat wij van énen bloede zijn! Mocht de oprichting van het gedenkteeken roor Anastasius er iets toe bijdragen om de Nederlandsche Protestanten tot elkander te brengen, om het gebrokene te heelen, om het gescheidene te hereenigen, om door eendracht macht te maken, om den toekomenden tijd nader te brengen waarin het zijn zal ésne kudde en één herderl Dan zullen de engelen in den hemel zich over dezen dag verblïden.

Nog slechts enkele woorden mag ik tot u richten. Het kost mij geen moeite om van het woord afstand te doen. Aanstonds zal het gedenkteeken zelf tot u spreken, en het zal welsprekender zijn dan ik. Er zal een stem van uitgaan tot Garderen, tot allen die aan deze kerke- 
lijke gemeente behooren, zeggende: vaders, brengt hier uwe zonen; moeders, brengt uwe dochters, en verhaalt hun van een groot man, die in Stroe geboren was, en $\mathrm{nu}$ in de vier windstreken met eere wordt genoemd, omdat hij vroom en goed was, en een volgeling van Jezus verdiende te heeten.

Er zal een stem van uitgaan tot geheel Gelderland, zij zal tlinken over de heuvelen der Veluwe en weerkaatst worden door de bosschen, roepende: zege! zege! Het is niet vergeefsch to strijden voor de waarheid!

Er zal een stem van uitgaan tot alle Protestantsche christenen in Nederland: zoekt wat $\mathfrak{u}$ vereenigt!

Nog dit: wij zouden geen goede Gereformeeerden zijn, als wij ons schuldig maakten aan menschvergoding. Wij zijn er van doordrongen, dat alle menschelïke krachten en vermogens zijn uit God, uit wien, door wien en tot wien alle dingen zijn. Laat ons daarom alle lofspraak op Anastasius, allen roem en alle eer, die wij hem hebben toegebracht, samenvatten in dit eene: Soli Deo Gloria! Aan God alleen de eer! 